\title{
Communication
}

\section{Biomass-Derived Nitrogen-Doped Porous Carbon for Highly Efficient Ambient Electro-Synthesis of $\mathrm{NH}_{3}$}

\author{
Qinglin $\mathrm{Li}^{1,2}$, Xiufang Chen ${ }^{1,3}$ and Yong Yang ${ }^{1, *}$ \\ 1 CAS Key Laboratory of Bio-Based Materials, Qingdao Institute of Bioenergy and Bioprocess Technology, \\ Chinese Academy of Sciences, Qingdao 266101, China; iql@qibebt.ac.cn (Q.L.); chenxf@qibebt.ac.cn (X.C.) \\ 2 University of Chinese Academy of Sciences, Beijing 100049, China \\ 3 National Engineering Lab for Textile Fiber Materials \& Processing Technology (Zhejiang) Zhejiang Sci-Tech \\ University, Hangzhou 310018, China \\ * Correspondence: yangyong@qibebt.ac.cn
}

Received: 24 February 2020; Accepted: 17 March 2020; Published: 22 March 2020

check for updates

\begin{abstract}
In this communication, we report a biomass-derived nitrogen-doped porous carbon (named as $\mathrm{NC}-800$ ) as an electrocatalyst for the ambient conversion of $\mathrm{N}_{2}$ to $\mathrm{NH}_{3}$. The catalyst $\mathrm{NC}-800$ was prepared from naturally renewable and easily available bamboo shoots, with inherently an approximate $8 \mathrm{wt} \%$ of $\mathrm{N}$-containing components, such as the $\mathrm{N}$ source, in a cost-effective and environmentally benign manner. This exhibited remarkable catalytic activity with a large $\mathrm{NH}_{3}$ yield and a Faradaic efficiency as high as $16.3 \mu \mathrm{g} \mathrm{h} \mathrm{hg}^{-1}$ cat and $27.5 \%$, respectively, at $-0.35 \mathrm{~V}$ versus a reversible hydrogen electrode (RHE) in $0.1 \mathrm{M} \mathrm{HCl}$ solution at ambient conditions. More importantly, the catalyst NC-800 demonstrated excellent electrochemical selectivity and stability.
\end{abstract}

Keywords: $\mathrm{N}_{2}$ fixation; $\mathrm{NH}_{3}$ production; biomass-derived carbon; electrocatalysis; $\mathrm{N}$-doping

\section{Introduction}

Ammonia $\left(\mathrm{NH}_{3}\right)$, as one of the most important chemicals for industry, has been widely used as a source to synthesize fertilizer, plastics, pharmaceuticals, explosives, and so on [1]. As a high-efficiency and carbon-free energy carrier, with a hydrogen capacity of $17.8 \mathrm{wt} \%$ [2], $\mathrm{NH}_{3}$ is also considered as a promising candidate for the future renewable energy economy. The ever-increasing demand for $\mathrm{NH}_{3}$ drives more and more attention toward artificial $\mathrm{N}_{2}$ fixation. However, the current industrial $\mathrm{NH}_{3}$ synthesis still dominantly depends on the energy-intensive Haber-Bosch process, leading to massive fossil fuel consumption and serious greenhouse gas emissions $[3,4]$. Therefore, it is highly desirable to develop more efficient and energy-saving synthetic routes for $\mathrm{NH}_{3}$ production.

Over the past few decades, great efforts have been devoted to the sustainable synthesis of $\mathrm{NH}_{3}$ from nitrogen, including biomimetic catalysis, photo catalysis, and photo(electro)catalysis [5-7]. Apart from the development of synthetic strategies, the detection methods for quantification of the produced ammonia were also developed accordingly [8,9]. Among all of the synthetic routes, electrocatalytic $\mathrm{N}_{2}$ reduction to $\mathrm{NH}_{3}$, ideally operating under ambient conditions with water as the hydrogen source, has been considered as a sustainable and effective way for $\mathrm{N}_{2}$ fixation and $\mathrm{NH}_{3}$ production, especially when it is powered by renewable electricity (e.g., solar and wind) [10]. Consequently, various metal-based and metal-free catalysts have been developed for the synthesis of $\mathrm{NH}_{3}$ under mild conditions via the electrochemical $\mathrm{N}_{2}$ reduction reaction (NRR) [11,12]. However, the efficiency of $\mathrm{NH}_{3}$ production is still far from comparable to that of the Haber-Bosch process, due to the extreme difficulty in breaking the strong $\mathrm{N} \equiv \mathrm{N}$ triple bond of $\mathrm{N}_{2}$ and the competing hydrogen evolution reaction (HER) during the electrocatalysis. Among those developed electrocatalysts, metal-free carbon-based catalysts are more intriguing because of their unique features, such as low-costs, large surface areas, mechanical flexibility 
with good electronic conductivity, and robust tolerance to acidic and/or alkaline conditions [13]. As a consequence, a number of carbon-based materials have been developed for $\mathrm{NRR}$ to $\mathrm{NH}_{3}$ production, specifically, heteroatom- (e.g., O [14], N [15], S [16], B [17], F [18], Cl [12], and P [19]) doped carbon materials, which demonstrated highly improved catalytic efficiency. Despite great progress, the current approaches for the introduction of heteroatoms into porous carbon significantly suffer from high-costs and tedious preparation procedures, with the utilization of complicated and expensive starting materials, e.g., metal organic frameworks (MOFs) [20], and metal-ligands complexes [21], which greatly limit their large scale-up for practical applications. Ideally, from both cost-effective and eco-friendly viewpoints, heteroatoms-doped porous carbon materials can be directly prepared from naturally renewable and easily available materials in a facile and environmentally benign manner, and more importantly can enable a highly efficient conversion of $\mathrm{N}_{2}$ to $\mathrm{NH}_{3}$ via the ambient NRR process, which are perfect candidates and will be the ultimate goal for chemists [14,22].

Recently, we have developed a facile and environmentally friendly method for the preparation of $\mathrm{N}$-doped porous carbon with a large surface area, and hierarchical pores from naturally available and renewable biomass-bamboo shoots as the starting material [23]. In this process, the approximate $8 \mathrm{wt} \%$ of $\mathrm{N}$-containing compositions, including the proteins and amino acids in bamboo shoots, was effectively decomposed to $\mathrm{N}$ atoms and incorporated into carbon lattices via pyrolysis under high temperature. In this work, we report such a biomass-derived $\mathrm{N}$-doped porous carbon can electrochemically convert $\mathrm{N}_{2}$ into $\mathrm{NH}_{3}$ at room temperature and with atmospheric pressure in an acidic aqueous solution. In $0.1 \mathrm{M} \mathrm{HCl}$, the rate of $\mathrm{NH}_{3}$ production and Faradaic efficiency (FE) are as high as $16.3 \mu \mathrm{g} \mathrm{h}^{-1} \mathrm{mg}^{-1}$ cat and $27.5 \%$, respectively, at $-0.35 \mathrm{~V}$ versus a reversible hydrogen electrode (RHE). To the best of our knowledge, these performance metrics are unprecedented and the highest value for the electrocatalytic production of $\mathrm{NH}_{3}$ from $\mathrm{N}_{2}$ under ambient conditions at such a lower potential, compared with those previous results catalyzed by metal-free carbon-based materials [12,24].

\section{Results and Discussion}

The biomass-derived nitrogen-doped porous carbon was prepared through a facile hydrothermal-pyrolysis process, as shown in Scheme 1a. Typically, fresh bamboo shoots were first cut into small pieces, dried, and ground into powder, followed by the hydrothermal carbonization process in a Teflon-inner stainless-steel autoclave, with deionized water at $180^{\circ} \mathrm{C}$ to obtain the biochar, which was then filtered, washed thoroughly with deionized water and dried under vacuum at $60^{\circ} \mathrm{C}$. Finally, the obtained brown biochar was pyrolyzed at 600,800 , and $1000{ }^{\circ} \mathrm{C}$, respectively, under an $\mathrm{N}_{2}$ atmosphere for $4 \mathrm{~h}$ at the heating rate of $5{ }^{\circ} \mathrm{C} \mathrm{min}^{-1}$. The prepared catalysts were named as NC-T, where $\mathrm{T}$ represents the pyrolysis temperature. Note that, toxic or environmentally unfriendly activating agents [25,26], e.g., $\mathrm{KOH}, \mathrm{ZnCl}_{2}$, or $\mathrm{H}_{3} \mathrm{PO}_{4}$, are not required for carbonization in this process, making this method cost-effective and sustainable.

Comprehensive characterizations, including XRD, Raman, BET, HR-TEM, and XPS, were performed to disclose the physical and chemical features of the NC-800. The TEM image (Scheme 1b) shows that it has a loose and interconnected structure with formation of interstitial porosity and graphitic carbon layers. HR-TEM images (Scheme 1c,d) show the well-resolved lattice spacing of $0.34 \mathrm{~nm}$ corresponding to the (002) plane of graphitic carbon. The High-angle annular dark-field scanning TEM (HAADF-STEM) image and elemental mapping (Scheme 1e) indicate that $\mathrm{N}$ atoms were homogeneously distributed on graphitic carbon. XRD pattern (Scheme 1f) reveals a graphitic carbon structure with characteristic peaks at $2 \theta=23$ and $43^{\circ}$, corresponding to (002) and (100) reflection planes, which is consistent with the HR-TEM results. The formation of the graphitic order with a certain degree of defects on the NC-800, induced by high temperature pyrolysis, was further confirmed by Raman spectrum, with observation of two characteristic $D\left(1330 \mathrm{~cm}^{-1}\right)$ and $G$ bands $\left(1590 \mathrm{~cm}^{-1}\right)$ (Scheme 1g) [27]. The XPS for NC exhibits typical C, N, and O peaks (Figures S1, S2, and S3). N 1s XPS spectrum (Scheme $1 \mathrm{~h}$ ) reveals that three types of $\mathrm{N}$ species, i.e., pyridinic- $(398.4 \mathrm{eV})$, pyrrolic$(399.7 \mathrm{eV})$ and graphitic-N $(400.9 \mathrm{eV})$, were embedded into the graphitic carbon structure [28], and the 
populations of them are $25.7 \%, 6.7 \%$, and $67.6 \%$, respectively. The pyridinic-N and pyrrolic-N were considered as dangling bonds to activate the $\mathrm{N}_{2}$ molecule [22]. BET analysis (Figure S6) indicates that the NC-800 has a large specific surface area $\left(913.7 \mathrm{~m}^{2} \mathrm{~g}^{-1}\right)$, and a hierarchical micro-meso-macroporous structure (Table S1). The large specific surface area and the hierarchical structure could lead to the excellent NRR performance for NC-800. The N content in the catalyst NC-800 was estimated to be $3.05 \mathrm{wt} \%$ by elemental analysis (Table S1). The large electronegativity of $\mathrm{N}$ (3.04) incorporated into the carbon lattices could induce the modification of charge density, electronic structure, and polarization charge, which lead to the strong adsorption of $\mathrm{N}_{2}$ for NC [7].

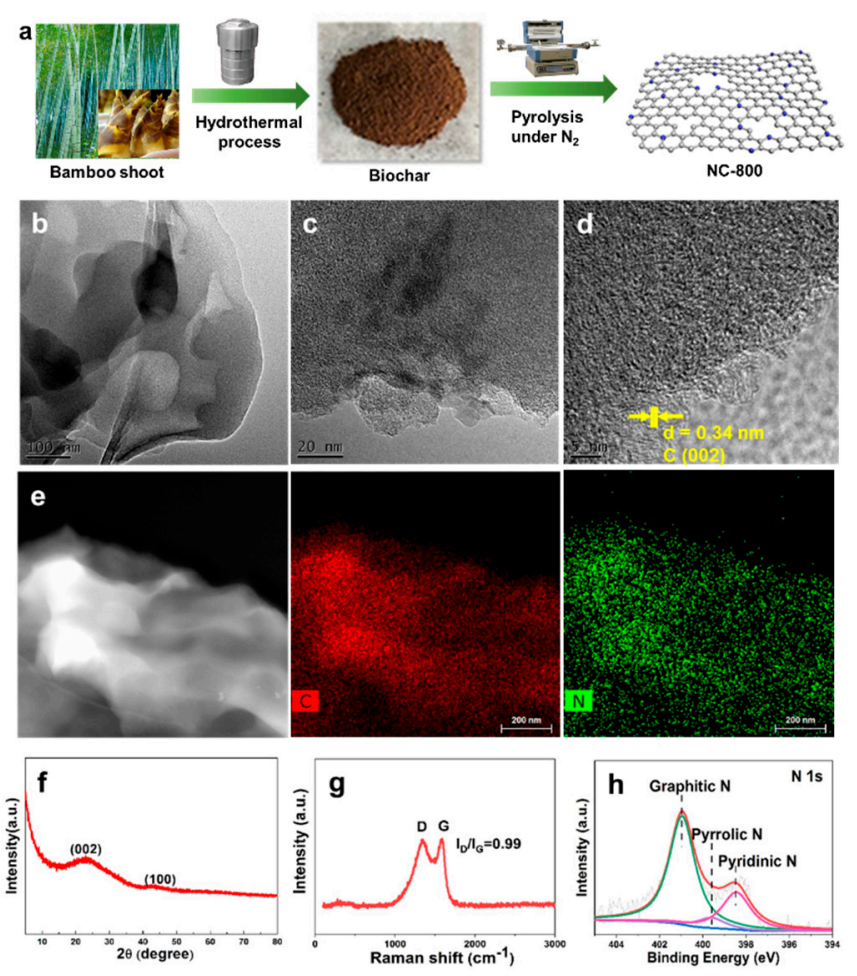

Scheme 1. (a) Schematic illustration of the fabrication process of bamboo shoots-derived NC-800. (b), (c), and (d) HRTEM images of the catalyst NC-800. (e) HAADF-HRTEM image of the NC-800 and corresponding elemental mapping of the NC-800. XRD pattern (f), Raman spectra (g), and N 1s XPS spectra (h) of the catalyst NC-800.

The ambient NRR performance of NC-800 was conducted in a typical H-cell, separated by a piece of Nafion membrane in an $\mathrm{N}_{2}$-saturated $\mathrm{HCl}(0.1 \mathrm{M})$ electrolyte (Figure $\mathrm{S} 8$ ). The catalyst NC-800 was deposited on carbon paper as the working electrode with $\mathrm{Ag} / \mathrm{AgCl}$ (saturated $\mathrm{KCl}$ electrolyte) as the reference in the cathode chamber, and a platinum plate as the counter electrode in the anode chamber. During electrolysis, $\mathrm{N}_{2}$ gas was bubbled into the cathode, where $\mathrm{H}^{+}$protons transported through the electrolyte could react with $\mathrm{N}_{2}$ adsorbed on the surface of the catalyst, to produce $\mathrm{NH}_{3}$. All potentials are recorded with respect to an RHE scale. The concentrations of the produced $\mathrm{NH}_{3}$ were spectrophotometrically determined using the indophenol blue method and ion chromatography method (Figures S9 and S15) [29], and the possible $\mathrm{N}_{2} \mathrm{H}_{4}$ as a by-product was evaluated using the Watt and Chrisp method (Figure S11) [30].

In order to assure the potential range of NRR for the catalyst NC-800, the linear sweep voltammetry (LSV) curves were measured in an Ar- and $\mathrm{N}_{2}$-saturated $\mathrm{HCl}$ solution. When the potential is more negative than $-0.35 \mathrm{~V}$ (vs. RHE), the current density of NC-800 under $\mathrm{N}_{2}$ increases obviously in comparison with that under $\mathrm{Ar}$, demonstrating that electrocatalytic $\mathrm{N}_{2}$ reduction occurs on NC-800 with an onset potential of $-0.25 \mathrm{~V}$ (Figure 1a). The time-dependent current density curves over NC-800 from -0.25 to $-0.50 \mathrm{~V}$ were collected over $2 \mathrm{~h}$ and are presented in Figure $1 \mathrm{~b}$. The corresponding 
UV/Vis absorption spectra of the electrolytes stained with indophenol blue indicator were displayed in Figure 1c. Both results show that the peak of the highest absorbance intensity is located at $-0.35 \mathrm{~V}$. The corresponding FEs and $\mathrm{NH}_{3}$ yields at different potentials are plotted in Figure 1d. Both FEs and $\mathrm{NH}_{3}$ yields increase at negatively applied potentials until $-0.35 \mathrm{~V}$, and then decrease gradually, which is ascribed to the competitive selectivity toward the hydrogen evolution reaction (HER) [12,31,32]. The highest FE (27.5\%) and maximum $\mathrm{NH}_{3}$ yield of $16.3 \mu \mathrm{g} \mathrm{h}^{-1} \mathrm{mg}^{-1}$ cat are achieved at $-0.35 \mathrm{~V}$ vs. RHE, which is comparable and even superior to those of mostly reported results catalyzed by metal-free carbon or even metal-based catalysts. A more detailed comparison is compiled in Table S3. To ensure the reliability and accuracy of the obtained catalytic activity, the ion chromatography method was also adopted for $\mathrm{NH}_{3}$ quantification, and a $\mathrm{NH}_{3}$ yield $\left(15.13 \mu \mathrm{g} \mathrm{h}^{-1} \mathrm{mg}^{-1}\right.$ cat $)$ very close to that of the indophenol blue method was observed (Figure 1e). Moreover, $\mathrm{N}_{2} \mathrm{H}_{4}$ was not detected at all potentials during the NRR process (Figure S12), indicative of a $100 \%$ selectivity of NC-800 for the electrocatalytic $\mathrm{N}_{2}$ reduction to $\mathrm{NH}_{3}$. In addition, for comparison, NC-600 and NC-1000 were also used as the electrocatalysts to assess their catalytic performance at $-0.35 \mathrm{~V}$ under identical conditions, and it turned out that $\mathrm{NC}-800$ gave the best $\mathrm{FEs}$ and $\mathrm{NH}_{3}$ yield (Figure S13). The outstanding electrochemical NRR performance of NC-800 can be attributed to the following two reasons. Firstly, the large specific surface area makes active sites more accessible for electrochemical $\mathrm{N}_{2}-\mathrm{NH}_{3}$, while the abundance of micropores in the NC-800 could accelerate the electron and mass transfer process (Figure S6). Secondly, the presence of pyridinic- $\mathrm{N}$ on carbon could function as the active sites to facilitate the activation of $\mathrm{N}_{2}$ molecule. Therefore, NC-800 was used as the ideal catalyst for further investigation.
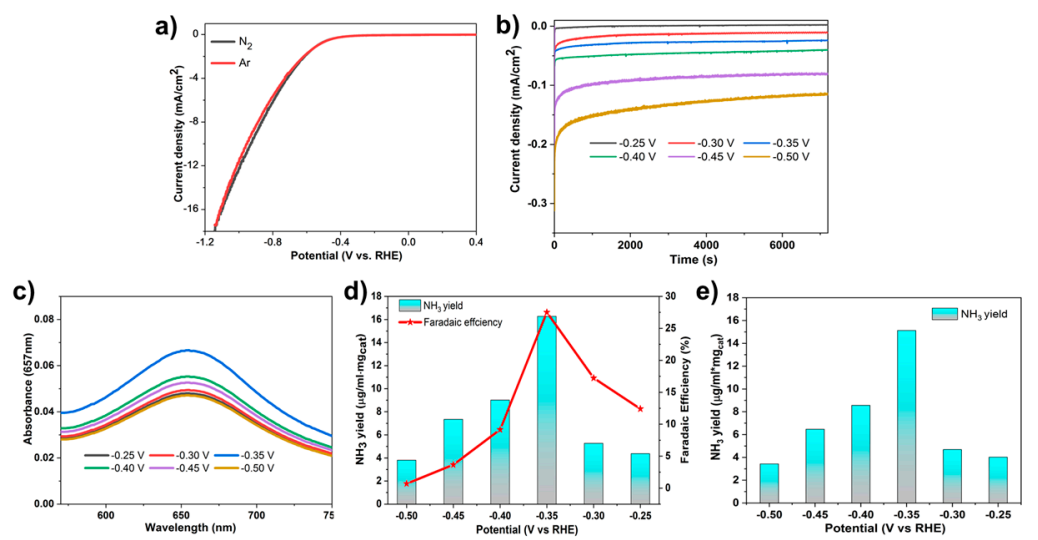

Figure 1. (a) Linear sweep voltammetry (LSV) curves for the catalyst NC-800 in Ar- and $\mathrm{N}_{2}$-saturated $0.1 \mathrm{M} \mathrm{HCl}$. (b) Time-dependent current density curves of $\mathrm{NC}$ at a suit of potentials for $2 \mathrm{~h}$ in $\mathrm{N}_{2}$-saturated $0.1 \mathrm{M} \mathrm{HCl}$. (c) UV-Vis absorption spectra of the electrolyte colored with indophenol indicator for $2 \mathrm{~h}$. (d) The obtained $\mathrm{NH}_{3}$ yield rates and Faradaic efficiency (FEs) for NC-800 at different potentials. (e) The obtained $\mathrm{NH}_{3}$ yield rates for $\mathrm{NC}$ under various potentials determined by ion chromatography.

To verify that the detected $\mathrm{NH}_{3}$ was generated through the NRR process over NC-800, the electrolysis was carried out in either $\mathrm{N}_{2}$-saturated solution at open circuit potential or Ar-saturated solution at $-0.35 \mathrm{~V}$ (vs. RHE) for $2 \mathrm{~h}$ [33]. In either case, almost no $\mathrm{NH}_{3}$ was detected (Figure 2a), strongly suggesting that the $\mathrm{NH}_{3}$ was produced exclusively from the NRR reaction catalyzed by NC-800 electrode. Furthermore, a linear correlation between $\mathrm{m}_{\mathrm{NH} 3}$ and the reaction time of electrolysis was also observed, as shown in Figure $2 \mathrm{~b}$. To further confirm the $\mathrm{N}$ source of the $\mathrm{NH}_{3}$ product during NRR process, we also performed the ${ }^{15} \mathrm{~N}$ isotopic measurements using ${ }^{15} \mathrm{~N}_{2}$ as the feeding gas. As shown in Figure 2e, there is a distinguishable chemical shift of a doublet pattern with a coupling constant of ${ }^{1} J_{\mathrm{N}-\mathrm{H}}$ $=72 \mathrm{~Hz}$ for ${ }^{15} \mathrm{NH}_{4}{ }^{+} \mathrm{NRR}$ samples, indicating that ammonia is produced via electrochemical nitrogen reduction. In contrast, a triplet coupling with the ${ }^{1} J_{\mathrm{N}-\mathrm{H}}=52 \mathrm{~Hz}$ for ${ }^{14} \mathrm{NH}_{4}{ }^{+}$samples are observed when using ${ }^{14} \mathrm{~N}_{2}$ as the feeding gas and there is no detectable amount of ammonia in the Ar-feeding electrolyte, which further confirms that the $\mathrm{N}$ source of ammonia is $\mathrm{N}_{2}$ gas. Of note, to exclude any 
contamination of $\mathrm{NH}_{3}$ production originating from the surroundings, nitrogen and argon gas were pre-purified by passing a glass vessel containing $0.1 \mathrm{M} \mathrm{NaOH}(50 \mathrm{~mL})$ solution before feeding into the cathode. In addition, detection of any ammonia formation from the electrolyte was also analyzed before each NRR test. Besides, the electrolytes of the tail gas trap combined with the anode chamber were also detected, and the results show that the ammonia production was negligible. Taking all results into account, we can safely conclude that $\mathrm{NH}_{3}$ did originate from the NRR catalyzed by NC-800.

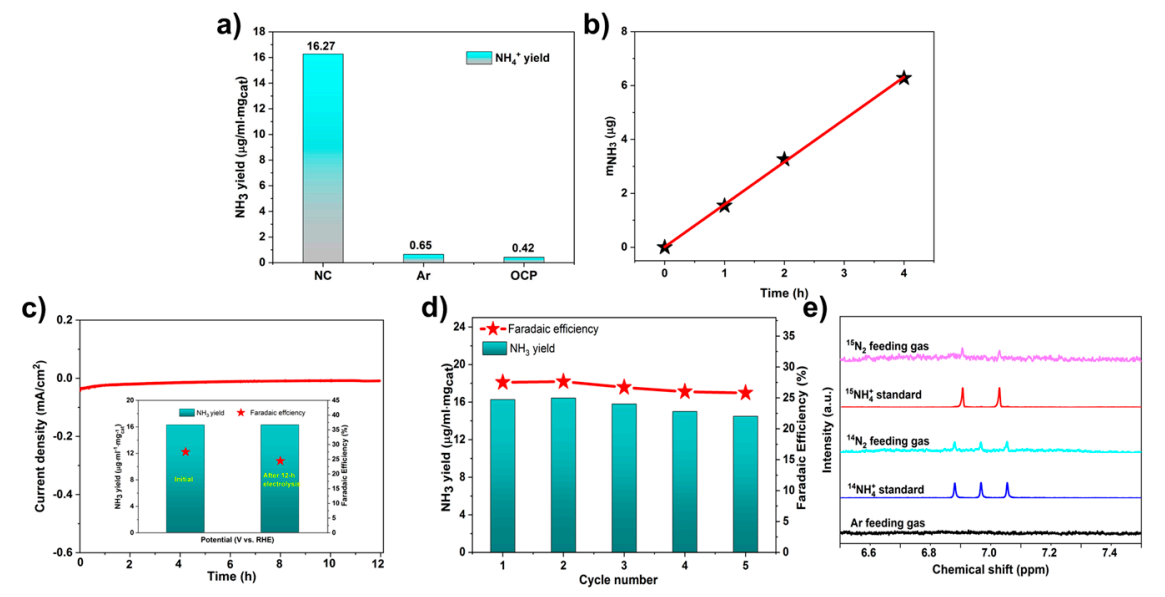

Figure 2. (a) The $\mathrm{NH}_{3}$ production for $\mathrm{NC}$ under various conditions: at $-0.35 \mathrm{~V}$ in $\mathrm{N}_{2}$, open circuit in $\mathrm{N}_{2}$, and $-0.35 \mathrm{~V}$ in Ar for $2 \mathrm{~h}$. (b) The curve of $\mathrm{NH}_{3}$ production versus reaction time at $-0.35 \mathrm{~V}$. (c) The time-dependent current density curve for $\mathrm{NC}$ at $-0.35 \mathrm{~V}$ in $\mathrm{N}_{2}$ for $12 \mathrm{~h}$ (inset, $\mathrm{NH}_{3}$ yield rates and FEs for $\mathrm{NC}$ before and after $12 \mathrm{~h}$ at $-0.35 \mathrm{~V}$ ). (d) The $\mathrm{NH}_{3}$ yield rates and FEs for $\mathrm{NC}$ at $-0.35 \mathrm{~V}$ over 5 cycles. (e) $1 \mathrm{H}$ NMR spectra of the electrolytes after NRR electrolysis on NC for $2 \mathrm{~h}$ using $\mathrm{Ar}$ gas, ${ }^{14} \mathrm{~N}_{2}$ gas, ${ }^{15} \mathrm{~N}_{2}$ gas as the feeding gas.

The stability of an electrocatalyst is a key factor for its practical application. We subsequently investigated the electrolytic performance of the catalyst NC-800 for successive uses. As presented in Figure 2d, the $\mathrm{NH}_{3}$ yields and FEs show a slight variation after five consecutive recycling tests, indicating the high stability of $\mathrm{NC}$ during the $\mathrm{N}_{2}$ reduction process. Meanwhile, small attenuation in the current density of the chronoamperometric measurements was also observed after around $12 \mathrm{~h}$ of NRR electrolysis at $-0.35 \mathrm{~V}$ (Figure 2c). In addition, the used catalyst NC-800 also demonstrated $\mathrm{NH}_{3}$ yield (16.28 $\mu \mathrm{g} \mathrm{h}^{-1} \mathrm{mg}^{-1}$ cat) and FEs (24.43\%) for NRR electrolysis under identical conditions, which is equal to that obtained from the fresh NC-800 (Table S2). All of these results further confirm the long-term electrochemical durability of the catalyst NC-800.

Previous reports regarding the NRR process electrocatalyzed by N-doped carbon as the catalyst reveal that pyridinic and pyrrolic $\mathrm{N}$ moieties incorporated in a graphitic layer, together with the generated adjacent atomic vacancy (e.g., $\mathrm{C}$ and $\mathrm{N}$ ), are active sites for adsorbing and activating the $\mathrm{N}_{2}$ molecule to initiate the conversion of $\mathrm{N}_{2}$ to $\mathrm{NH}_{3}[13,22]$. Thus, we consider the present catalyst similar to those previously reported catalysts in catalytically active sites and a preferable electrochemical reaction pathway for $\mathrm{NH}_{3}$ synthesis on NC-800. To further verify this, density functional theory (DFT) calculations were conducted (Scheme S1 and Figure S17). Our theoretical calculations reveal that two adjacent pyridinic-N vacancy species in the graphitic carbon structure can form a strong interaction with the molecule $\mathrm{N}_{2}$ in a very stable structure, which can be hydrogenated by the proton $\mathrm{H}^{+}$, followed by the process N-N $\rightarrow \mathrm{N}-\mathrm{NH} \rightarrow \mathrm{HN}-\mathrm{NH} \rightarrow \mathrm{HN}-\mathrm{NH}_{2} \rightarrow \mathrm{HN}-\mathrm{NH}_{3}$ to generate $\mathrm{NH}_{3}$ molecule and simultaneously create the $\mathrm{N}$ vacancies for further $\mathrm{N}_{2}$ adsorption and activation. Such a finding is in line with previous reports $[13,22,34]$. 


\section{Conclusions}

In summary, we report a hierarchically porous $\mathrm{N}$-doped carbon (NC-800), derived from $\mathrm{N}$-containing bamboo shoots, as a catalyst for the ambient electrochemical conversion of $\mathrm{N}_{2}$ to $\mathrm{NH}_{3}$. A large $\mathrm{NH}_{3}$ yield and a Faradaic efficiency as high as $16.3 \mu \mathrm{gh}^{-1} \mathrm{mg}^{-1}$ cat and $27.5 \%$, respectively, were achieved at $-0.35 \mathrm{~V}$ versus a reversible hydrogen electrode (RHE) in $0.1 \mathrm{M} \mathrm{HCl}$ solution at ambient conditions. More importantly, the NC-800 also exhibited excellent electrochemical selectivity and stability. Our work opens a new avenue to develop various metal-based catalysts for electrocatalysis using the hierarchically porous N-doped carbon.

Supplementary Materials: The following are available online at http://www.mdpi.com/2073-4344/10/3/353/s1, Figure S1. N 1s XPS spectra for the catalysts NC-600, 800, 1000. Figure S2. O 1s XPS spectra for the catalysts NC-600, 800, 1000. Figure S3. C 1s XPS spectra for the catalysts NC-600, 800, 1000. Figure S4. Raman spectra for the catalysts NC-600, 800, 1000. Figure S5. XRD pattern for the catalysts NC-600, 800, 1000. Figure S6. $\mathrm{N}_{2}$ adsorption-desorption isotherms and the pore size distributions of the prepared catalysts. Figure S7. N2-TPD profiles of the NC-600, NC-800 and NC-1000 catalysts. Figure S8. The photograph of H-cell with three-electrode cell and the working electrode connections of NRR process. Figure S9. (a) UV-vis curves of indophenol assays with $\mathrm{NH}_{4}{ }^{+}$ions after incubated for $2 \mathrm{~h}$ at $\mathrm{HCl}$ solution. (b) Concentration-absorbance curve of $\mathrm{NH}^{4+}$ ions with a serious of standard concentration at $\mathrm{HCl}$ solutions. Figure $\mathrm{S} 10$. UV-vis absorption spectra of the electrolytes stained with an indophenol indicator after NRR electrolysis. Figure S11. (a) UV-vis curves of Watt and Chrisp assays with $\mathrm{N}_{2} \mathrm{H}_{4}$ after incubated for $2 \mathrm{~h}$ at $\mathrm{HCl}$ solution (b) Concentration-absorbance curve of $\mathrm{N}_{2} \mathrm{H}_{4}$ solution with a serious of standard concentration at $\mathrm{HCl}$ solution. Figure $\mathrm{S} 12$. Determination of the formation of by-product $\mathrm{N}_{2} \mathrm{H}_{4}$ over the $\mathrm{NC}-800$ at different potential (vs. RHE). Figure S13. The $\mathrm{NH}_{3}$ yield and FEs over the catalysts NC-600, 800 and 1000 at $-0.35 \mathrm{eV}$ (vs. RHE). Figure S14. The $\mathrm{NH}_{3}$ yield of the cathode chamber, tail gas trap, and anode chamber over the catalysts NC-800 at -0.35 V. Figure S15. (a) Ion chromatography of a suit of $\mathrm{NH}_{4}^{+}$ at $\mathrm{HCl}$ solution. (b) Concentration-area curve of $\mathrm{NH}_{4}{ }^{+}$ions with a serious of standard concentration at $\mathrm{HCl}$ solutions. Figure S16. UV-vis absorption spectra of the electrolytes stained with an indophenol indicator after NRR electrolysis. Figure S17. The Mars-van-Krevelen mechanism for electrochemical nitrogen reduction reaction to ammonia on NC-800. The free energy profiles and the structures of intermediates are shown in the reaction path. Scheme S1. a) Side view, and b) top view of the optimized pyridinic-N doped graphitic porous carbon structures along the hydrogenation process. Table S1. Chemical composition and texture properties of the catalyst NC-T. Table S2. Chemical composition and $\mathrm{NH}_{3}$ yield and FEs of the catalyst fresh- and used-NC-800.

Author Contributions: Conceptualization, Q.L., X.C. and Y.Y.; Investigation, Q.L.; Methodology, Q.L.; Project administration, X.C. and Y.Y.; Supervision, Y.Y.; Writing-original draft, Q.L. and Y.Y. All authors have read and agreed to the published version of the manuscript.

Funding: The authors would like to acknowledge the financial support from the Key Technology R\&D Program of Shandong Province (2019GGX102075), Open Projects of State Key Laboratory of Physical Chemistry of the Solid Surface (Xiamen University) (No. 201808), and the 13th-Five Key Project of the Chinese Academy of Sciences (Grant No. Y7720519KL). Y.Y also acknowledges the support from the Royal Society (UK) for a Newton Advanced Fellowship (NAF\R2\180695).

Conflicts of Interest: The authors declare no conflict of interest.

\section{References}

1. Robert, F.S. Chemistry. New recipe produces ammonia from air, water, and sunlight. Science 2014, 345, 610.

2. Wang, W.T.; Herreros, J.M.; Tsolakis, A.; York, A.P.E. Ammonia as hydrogen carrier for transportation; investigation of the ammonia exhaust gas fuel reforming. Int. J. Hydrogen Energy 2013, 38, 9907-9917. [CrossRef]

3. Van der Ham, C.J.M.; Koper, M.T.M.; Hetterscheid, D.G.H. Challenges in reduction of dinitrogen by proton and electron transfer. Chem. Soc. Rev. 2014, 43, 5183-5191. [CrossRef] [PubMed]

4. Kandemir, T.; Schuster, M.E.; Senyshyn, A.; Behrens, M.; Schlögl, R. The Haber-Bosch process revisited: On the real structure and stability of "ammonia iron" under working conditions. Angew. Chem. Int. Ed. 2013, 52, 12723-12726. [CrossRef]

5. Broda, H.; Tuczek, F. Catalytic ammonia synthesis in homogeneous solution-Biomimetic at last? Angew. Chem. Int. Ed. 2014, 53, 632-634. [CrossRef]

6. Chen, X.Z.; Li, N.; Kong, Z.Z.; Ong, W.J.; Zhao, X.J. Photocatalytic fixation of nitrogen to ammonia: State-of-the-art advancements and future prospects. Mater. Horiz. 2018, 5, 9-27. [CrossRef] 
7. Chen, X.R.; Guo, Y.T.; Du, X.C.; Zeng, Y.S.; Chu, J.W.; Gong, C.H.; Huang, J.W.; Fan, C.; Wang, X.F.; Xiong, J. Atomic structure modification for electrochemical nitrogen reduction to ammonia. Adv. Energy Mater. 2019, 10, 1903172. [CrossRef]

8. Zhao, Y.X.; Shi, R.; Bian, X.A.; Zhou, C.; Zhao, Y.F.; Zhang, S.; Wu, F.; Waterhouse, G.I.N.; Wu, L.Z.; Tung, C.H.; et al. Ammonia detection methods in photocatalytic and electrocatalytic experiments: How to improve the reliability of $\mathrm{NH}_{3}$ production rates? Adv. Sci. 2019, 6, 1802109. [CrossRef]

9. Andersen, S.Z.; Čolić, V.; Yang, S.G.; Schwalbe, J.A.; Nielander, A.C.; MacEnaney, J.M.; Rasmussen, K.E.; Baker, J.G.; Singh, A.R.; Rohr, B.A.; et al. A rigorous electrochemical ammonia synthesis protocol with quantitative isotope measurements. Nature 2019, 570, 504-508. [CrossRef]

10. Suryanto, B.H.R.; Du, H.L.; Wang, D.B.; Chen, J.; Simonov, A.N.; MacFarlane, D.R. Challenges and prospects in the catalysis of electroreduction of nitrogen to ammonia. Nat. Catal. 2019, 2, 290-296. [CrossRef]

11. Xu, B.; Liu, Z.C.; Qiu, W.B.; Liu, Q.; Sun, X.P.; Cui, G.W.; Wu, Y.P.; Xiong, X.L. $\mathrm{La}_{2} \mathrm{O}_{3}$ nanoplate: An efficient electrocatalyst for artificial $\mathrm{N}_{2}$ fixation to $\mathrm{NH}_{3}$ with excellent selectivity at ambient condition. Electrochim. Acta 2019, 298, 106-111. [CrossRef]

12. Zang, W.J.; Yang, T.; Zou, H.Y.; Xi, S.B.; Zhang, H.; Liu, X.M.; Kou, Z.K.; Du, Y.H.; Feng, Y.P.; Shen, L.; et al. Copper single atoms anchored in porous nitrogen-doped carbon as efficient $\mathrm{pH}$-Universal catalysts for the nitrogen reduction reaction. ACS Catal. 2019, 9, 10166-10173. [CrossRef]

13. Zhao, S.L.; Lu, X.Y.; Wang, L.Z.; Gale, J.L.; Amal, R. Carbon-based metal-free catalysts for electrocatalytic reduction of nitrogen for synthesis of ammonia at ambient conditions. Adv. Mater. 2019, 31, 1805367. [CrossRef] [PubMed]

14. Wu, T.T.; Li, P.P.; Wang, H.B.; Zhao, R.B.; Zhou, Q.; Kong, W.H.; Liu, M.L.; Zhang, Y.Y.; Sun, X.P.; Gong, F.F. Biomass-derived oxygen-doped hollow carbon microtubes for electrocatalytic $\mathrm{N}_{2}$-to- $\mathrm{NH}_{3}$ fixation under ambient conditions. Chem. Commun. 2019, 55, 2684-2687. [CrossRef]

15. Kong, Y.; Li, Y.; Yang, B.; Li, Z.J.; Yao, Y.; Lu, J.G.; Lei, L.C.; Wen, Z.H.; Shao, M.H.; Hou, Y. Boron and nitrogen co-doped porous carbon nanofibers as metal-free electrocatalysts for highly efficient ammonia electrosynthesis. J. Mater. Chem. A 2019, 7, 26272-26278. [CrossRef]

16. Xia, L.; Yang, J.J.; Wang, H.B.; Zhao, R.B.; Chen, H.Y.; Fang, W.H.; Asiri, A.M.; Xie, F.Y.; Cui, G.L.; Sun, X.P. Sulfur-doped graphene for efficient electrocatalytic $\mathrm{N}_{2}$-to- $\mathrm{NH}_{3}$ fixation. Chem. Commun. 2019, 55, 3371-3374. [CrossRef]

17. Yu, X.M.; Han, P.; Wei, Z.Z.; Huang, L.S.; Gu, Z.X.; Peng, S.J.; Ma, J.M.; Zheng, G.F. Boron-doped graphene for electrocatalytic $\mathrm{N}_{2}$ reduction. Joule 2018, 2, 1610-1622. [CrossRef]

18. Yuan, D.; Wei, Z.X.; Han, P.; Yang, C.; Huang, L.S.; Gu, Z.X.; Ding, Y.; Ma, J.M.; Zheng, G.F. Electron distribution tuning of fluorine-doped carbon for ammonia electrosynthesis. J. Mater. Chem. A 2019, 7, 16979-16983. [CrossRef]

19. Song, P.F.; Wang, H.; Kang, L.; Rang, B.C.; Song, H.H.; Wang, R.M. Electrochemical nitrogen reduction to ammonia at ambient conditions on nitrogen and phosphorus co-doped porous carbon. Chem. Commun. 2019, 55, 687-690. [CrossRef]

20. Wang, T.T.; Zhao, Q.D.; Fu, Y.Y.; Lei, C.J.; Yang, B.; Li, Z.J.; Lei, L.C.; Wu, G.; Hou, Y. Carbon-Rich nonprecious metal single atom electrocatalysts for $\mathrm{CO}_{2}$ reduction and hydrogen evolution. Small Methods 2019, 3, 1900210. [CrossRef]

21. Signarvic, R.S.; Degrado, W.F. Metal-binding dependent disruption of membranes by designed helices. J. Am. Chem. Soc. 2009, 131, 3377-3384. [CrossRef]

22. Zhao, C.J.; Zhang, S.B.; Hu, M.M.; Zhang, X.; Liu, Y.Y.; Li, W.Y.; Chen, C.; Wang, G.Z.; Zhang, H.M.; Zhao, H.J. Ambient electrosynthesis of ammonia on a biomass-derived nitrogen-doped porous carbon electrocatalyst: Contribution of pyridinic nitrogen. ACS Energy Lett. 2019, 4, 377-383. [CrossRef]

23. Ji, G.J.; Duan, Y.N.; Zhang, S.C.; Fei, B.H.; Chen, X.F.; Yang, Y. Selective semihydrogenation of alkynes catalyzed by Pd nanoparticles immobilized on heteroatom-doped hierarchical porous carbon derived from bamboo shoots. ChemSusChem 2017, 10, 3427-3434. [CrossRef]

24. Chen, C.; Yang, D.F.; Wang, Y.; Zhou, Y.Y.; Zou, Y.Q.; Li, Y.F.; Wang, S.Y. B-N Pairs enriched defective carbon nanosheets for ammonia synthesis with high efficiency. Small 2019, 15, 1805029. [CrossRef]

25. Deng, Q.F.; Liu, L.; Lin, X.Z.; Du, G.; Liu, Y.; Yuan, Z.Y. Synthesis and $\mathrm{CO}_{2}$ capture properties of mesoporous carbon nitride materials. Chem. Eng. J. 2012, 203, 63-70. [CrossRef] 
26. Fan, X.; Zhang, L.; Zhang, G.; Shu, Z.; Shi, J. Chitosan derived nitrogen-doped microporous carbons for high performance $\mathrm{CO}_{2}$ capture. Carbon 2013, 61, 423-430. [CrossRef]

27. Song, T.; Ren, P.; Duan, Y.N.; Wang, Z.Z.; Chen, X.F.; Yang, Y. Cobalt nanocomposites on N-doped hierarchical porous carbon for highly selective formation of anilines and imines from nitroarenes. Green Chem. 2018, 20, 4629-4637. [CrossRef]

28. Wang, X.Y.; Zhao, Q.D.; Yang, B.; Li, Z.J.; Bo, Z.; Lam, K.H.; Adli, N.M.; Lei, L.C.; Wen, Z.H.; Wu, G.; et al. Emerging nanostructured carbon-based non-precious metal electrocatalysts for selective electrochemical $\mathrm{CO}_{2}$ reduction to CO. J. Mater. Chem. A 2019, 7, 25191-25202. [CrossRef]

29. Shi, M.M.; Bao, D.; Wulan, B.R.; Li, Y.H.; Zhang, Y.F.; Yan, J.M.; Jiang, Q. Au Sub-Nanoclusters on $\mathrm{TiO}_{2}$ toward highly efficient and selective electrocatalyst for $\mathrm{N}_{2}$ conversion to $\mathrm{NH}_{3}$ at ambient conditions. Adv. Mater. 2017, 29, 1606550. [CrossRef]

30. Watt, G.W.; Chrisp, J.D. Spectrophotometric method for determination of hydrazine. Anal. Chem. 1952, 24, 2006-2008. [CrossRef]

31. Zhou, F.L.; Azofra, L.M.; Ali, M.; Kar, M.; Simonov, A.N.; Mcdonnell-Worth, C.; Sun, C.H.; Zhang, X.Y.; Macfarlane, D.R. Electro-synthesis of ammonia from nitrogen at ambient temperature and pressure in ionic liquids. Energy Environ. Sci. 2017, 10, 2516-2520. [CrossRef]

32. Li, Y.; Zhang, Q.; Li, C.; Fan, H.N.; Luo, Q.B.; Liu, H.K.; Dou, S.X. Atomically dispersed metal dimer species with selective catalytic activity for nitrogen electrochemical reduction. J. Mater. Chem. A 2019, 7, 22242-22247. [CrossRef]

33. Tang, C.; Qiao, S.Z. How to explore ambient electrocatalytic nitrogen reduction reliably and insightfully. Chem. Soc. Rev. 2019, 48, 3166-3180. [CrossRef]

34. Wang, Z.H.; Hu, X.; Liu, Z.Z.; Zou, G.J.; Wang, G.N.; Zhang, K. Recent developments in polymeric carbon nitride-derived photocatalysts and electrocatalysts for nitrogen fixation. ACS Catal. 2019, 9, 10260-10278. [CrossRef]

(C) 2020 by the authors. Licensee MDPI, Basel, Switzerland. This article is an open access article distributed under the terms and conditions of the Creative Commons Attribution (CC BY) license (http://creativecommons.org/licenses/by/4.0/). 